American Journal of Environmental Sciences 5 (6): 727-739, 2009

ISSN 1553-345X

(C) 2009 Science Publications

\title{
Groundwater Resources Pollution Risk: Application of the Holman Method
}

\author{
${ }^{1}$ M. De Maio, ${ }^{2} \mathrm{C}$. Favaron and ${ }^{1}$ G. Nocerino \\ ${ }^{1}$ Department of Land, Environment and Geo-Engineering, \\ Politecnico di Torino, Corso Duca Degli Abruzzi 24, 10129 Torino, Italy \\ ${ }^{2}$ Department of Inter-university Territorial Studies and Planning, \\ Politecnico di Torino, Castello del Valentino, Viale Mattioli 39, 10125 Torino, Italy
}

\begin{abstract}
Problem statement: The aim of this study is to make an attempt to assess, through the application of the Holman Method, the effects that a careless management of human induced activities could have on aquifers and in particular on tapping wells used for human supply. Approach: The study had been applied to two different territories, as far as both the geomorphological and human induced aspects are concerned: the city of Aosta, the capital city of the Autonomous Aosta Valley region and three municipalities located in the centre of the Veneto region. Results: Thanks to the first results that had been obtained from the application of this method and other ones, it is hoped that a strategic territorial management approach will be adopted in the future so that the Groundwater Resources (GWR) can coexist with the economic and urban developments. Conclusion: All the analysis had been implemented utilizing a Geographical Information System (GIS).
\end{abstract}

Key words: Groundwater resources protection and enhancement, Holman method, hazard centers, hazard index

\section{INTRODUCTION}

The Holman method ${ }^{[10]}$ is applied to calculate the potential impact of Hazard Centers (HC) on Groundwater Resources (GWR) and in particular on tapping wells used for human consumption.

Application of the Holman method involves an accurate census of the types of $\mathrm{HC}$ that are present in the examined area in order to highlight the activities that are responsible to the greatest extent for the classification of the potential hazard.

It is therefore necessary to evaluate the different hazard factors (Table 1) and the different control factors (Table 2), whether natural or man made, that together determine or prevent groundwater pollution, for each HC.

Each well is therefore considered in relation to the nearest source of pollution and all the following characteristics are considered:

- The Hazard Factor index, which is calculated as the product of the hazard factor weights:

$$
\mathrm{HFI}=\mathrm{A} \times \mathrm{B} \times \mathrm{C} \times \mathrm{D}
$$
pollution of groundwater and also to draw up a

- The control factor index, which is calculated as the product of the control factors:

$$
\mathrm{CFI}=\mathrm{E} \times \mathrm{F} \times \mathrm{G}
$$

A weight that varies between 1 and $3(1=$ low hazard; $2=$ medium hazard; $3=$ high hazard) is established beforehand for each of the aforementioned factors; in the case of the same distance between two sources of pollution but with different impact, the

\begin{tabular}{|c|c|c|}
\hline Code & Description & Weight \\
\hline \multirow[t]{4}{*}{$\bar{A}$} & Potential toxicity of discharged pollutants & \\
\hline & Toxic chemicals & 3 \\
\hline & Pathogenic bacteria and viruses & 2 \\
\hline & Substances able to change organoleptic characteristics & 1 \\
\hline \multirow[t]{4}{*}{ B } & Potential concentration of discharged pollutants & \\
\hline & High concentration $(50-100 \%)$ & 3 \\
\hline & Medium concentration $(10-50 \%)$ & 2 \\
\hline & Low concentration $(<10 \%)$ & 1 \\
\hline \multirow[t]{4}{*}{$\mathrm{C}$} & Potential polluting load & \\
\hline & $>50 \mathrm{~L} \mathrm{~m}^{-2} \mathrm{day}^{-1}$ & 3 \\
\hline & $10-50 \mathrm{~L} \mathrm{~m}^{-2} \mathrm{day}^{-1}$ & 2 \\
\hline & $<10 \mathrm{~L} \mathrm{~m}^{-2}$ day $^{-1}$ & 1 \\
\hline \multirow[t]{4}{*}{$\mathrm{D}$} & Potential frequency of discharging pollutants & \\
\hline & $30-365$ day year ${ }^{-1}$ & 3 \\
\hline & $8-30$ day year ${ }^{-1}$ & 2 \\
\hline & $0-7$ day year ${ }^{-1}$ & 1 \\
\hline
\end{tabular}
source with the highest impact is considered.

Corresponding Author: M. De Maio, Department of Land, Environment and Geo-Engineering, Politecnico di Torino, Corso Duca degli Abruzzi 24, 10129 Torino, Italy Tel: +39 0115647685 
Am. J. Environ. Sci., 5 (6): 727-739, 2009

Table 2: Control Factor Index (CFI)

\begin{tabular}{lll}
\hline Code & Description & Weight \\
\hline E & Degree of natural protection: & \\
& Discharge in the underlying aquifer system & 3 \\
& Discharge in the soil & 2 \\
& Discharge on the soil surface & 1 \\
F & Degree of preventive control of the hazard centre: \\
& Poor & 3 \\
& Modest & 2 \\
& Elevated & 1 \\
Gelative distance to the closest polluting subject: & \\
& The hazard centre is on the upstream gradient \\
$\quad<1 \mathrm{~km}$ & 3 \\
$1-3 \mathrm{~km}$ & 2 \\
& $>3 \mathrm{~km}$ & 1 \\
& The hazard centre is on the downstream gradient & \\
$<0.5 \mathrm{~km}$ & 3 \\
$0.5-1 \mathrm{~km}$ & 2 \\
$>1 \mathrm{~km}$ & 1 \\
\hline
\end{tabular}

Table 3: Hazard index value range

\begin{tabular}{lllll}
\hline $\begin{array}{l}\text { Potential } \\
\text { impact }\end{array}$ & Low & Medium & High & Very high \\
\hline HI & $1 \leq \mathrm{IP} \geq 546$ & $547 \leq \mathrm{IP} \geq 1093$ & $1094 \leq \mathrm{IP} \geq 1640$ & $1641 \leq \mathrm{IP} \geq 2187$ \\
\hline
\end{tabular}

At this point, it is possible to calculate the Hazard Index (HI) for each $\mathrm{HC}$ as follows:

$$
\mathrm{HI}=\mathrm{HFI} \times \mathrm{CFI}
$$

The obtained values are divided into 4 categories, as shown in Table 3.

The system is useful to analyze two different levels of hazard, one connected to the possibility of pollution of a water point by a hazard centre (calculating the $\mathrm{HI}$ ) and another generated by the synergic action of different hazard centers of the same type on the groundwater resources, which leads to such a level of pollution that they become unusable for drinkable water supply (calculating the THI, the Territorial Hazard Index).

A comparison among the calculated hazard indices make it possible to assess the intervention priority, starting from the precondition that a low HI means a slight hazard of pollution of a determined water point, even over a long period of time, while an elevated HI means an elevated hazard, even for short periods of time.

The Territorial Hazard Index (THI) is calculated by multiplying the mean $\mathrm{HI}$ value relative to each homogeneous group of assessed $\mathrm{HC}$, expressed in thousandths, by the product of the presumed release surface (calculated in hectares) multiplied by the number of $\mathrm{HC}$ that make up the assessed homogeneous group:

$\mathrm{THI}=\left(\mathrm{HI}_{\text {average }} / 1000\right) \times \mathrm{S}[$ ha $] \times \mathrm{N}_{\text {hazard centers }}$

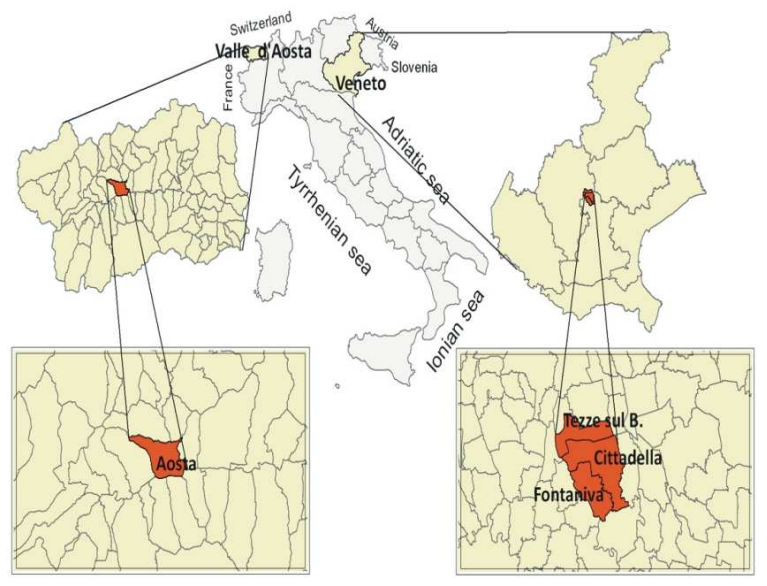

Fig. 1: Localization of study areas

The Holman method has been applied, in an experimental manner, in two study areas in North Italy (Fig. 1):

- North-West, in the autonomous Aosta Valley region

- North-East, in the Veneto region

The main difficulty involved in applying the Holman method is to recognize what the many risk situations are that could cause a spillage of pollutants into an aquifer ${ }^{[2]}$. Both accidental spillage,_during transport and the utilization of polluting substances during the conduction of activities and "uncontrolled" spillage, connected, for example, to the loss of pollutants from an underground tank are in fact possible.

In order to carry out this type of analysis, it is fundamental to have a high number of data available, through the assessing of all the HCs considered at risk to pollution and all the tapping wells used for human supply

A Geographical Information System (GIS) that collects these data in a standardized manner and that updates them does not exist at a national level. Each Local Organization that operates at a territorial level has set up a regional GIS, in relation to its own requirements and economic possibilities and, unfortunately, these are often imprecise and not updated and therefore unusable if not obsolete.

In the considered study areas and because of a lack of available data, it was first necessary to prepare a databank by collecting the necessary information from the public and private organizations operating throughout the territory. This was done through the drawing up of census cards (Table 4). The activity carried out, the relative geographic coordinates and the Holman method parameters relative to the hazard factors $(\mathrm{A}, \mathrm{B}$, 
Am. J. Environ. Sci., 5 (6): 727-739, 2009

Table 4: Example of an activity category card

\begin{tabular}{|c|c|c|c|c|c|c|c|c|c|c|c|c|c|c|c|c|c|c|c|}
\hline \multicolumn{6}{|c|}{ Details of the activity } & \multicolumn{14}{|c|}{ Holman parameters } \\
\hline \multirow[b]{2}{*}{ Company } & \multirow[b]{2}{*}{ Owner } & \multirow{2}{*}{$\begin{array}{l}\text { Activity } \\
\text { conducted }\end{array}$} & \multicolumn{2}{|c|}{$\begin{array}{l}\text { Geographic } \\
\text { coordinates }\end{array}$} & \multirow[b]{2}{*}{ Site } & \multicolumn{7}{|c|}{ Ordinary scenario } & \multicolumn{7}{|c|}{ Critical scenario } \\
\hline & & & $\mathrm{x}$ & $\mathrm{y}$ & & A $\mathrm{B}$ & C & D & E & $\mathrm{F}$ & $\mathrm{G}$ & $\mathrm{HI}$ & A & B & C & D & E & $\mathrm{F}$ & $\mathrm{G} \quad \mathrm{H}$ \\
\hline Company 1 & $\begin{array}{l}\text { Dr. Mario } \\
\text { Rossi }\end{array}$ & $\begin{array}{l}\text { Metallic } \\
\text { work }\end{array}$ & 399840 & 505617 & $\begin{array}{l}\text { Avenue } \\
\text { Torino, } 9\end{array}$ & & & & & & & & & & & & & & \\
\hline
\end{tabular}

C and D) and the control factors (E, F and G) were reported in each card and two potential impact risk scenarios were identified.

The first scenario represents the "normal scenario" which refers to the daily functioning of an activity; the second, defined as 2 "critical scenario", refers to the maximum risk situation that can be generated, considering all the variables connected to the development of the activity itself. The two scenarios that have been proposed thus allow the extreme infinite situations that can occur on a territory to be described. These extreme situations have been considered as it is useless, from the point of view of the time and results effort, to deal with such a large case study of situations. In this way, a specific weight was assigned to each factor relative to each activity category in order to take all the risk situations into consideration.

Before presenting the application and the results that were obtained using the Holman method, relative to each studied area, it is necessary to explain the motivation behind the assignment of the weights relative to the hazard and control factors for the main categories of activities considered ${ }^{[1,3,8]}$. The activities that had the greatest influence on the analyses, in relation to the number of activities present on the territory or the elevated pollution risk that they represented, are reported hereafter.

Only the parameters that are distant from each other in the two scenarios are explained in order to justify the choices that were undertaken; the weight relative to the parameter concerning the distance between the $\mathrm{HC}$ and the closest well (parameter G) varies in relation to the different situations and is therefore not reported according to activity category.

Garage-body shops: This category has been identified as a HC, since the activities carried out foresee the use of oils, greasy substances and fuels. The two scenarios differ because of:

- The potential polluting load $(\mathrm{C})$, in relation to the quantity and the type of pollutant dispersed during the activities
- The frequency (D), in relation to the probability that the spillage occurs or does not occur and to the operating level of the activity

- The preventive control degree $(\mathrm{F})$, in relation to the type of premises in which the activity is conducted

It is unlikely that the value is the maximum (3) because the activity is not conducted in the open air.

Dairies: This category is considered to be a $\mathrm{HC}$ because of the composition of the substances that are dealt with and because of the numerous procedures that the milk has to undergo before it can be put on the market (for example, pasteurization or skimming). If these substances were to be spilled, the aquifer would be compromised. The two scenarios differ because of:

- The potential concentration (B), in relation to the concentrations of the pollutants for which, although generally low in comparison to the volumes of effluents produced, two different dispersion situations were hypothesized

- The polluting load potential (C), in relation to the operating level of the dairy

- The preventive control degree $(\mathrm{F})$, in relation to the type of structure in which the activity is carried out and to the existence or the lack of monitoring

Breedings: The analyzed territories showed signs of the presence of different breeders. The two scenarios differ because of the potential toxicity of the discharged pollutants (parameter A) and the potential (C) and frequency (D) of the polluting discharge. These three hazard factors depend on the structures in which the activity is carried out and the existence or lack of adequate procedures for the collection of the highly polluting excrement.

Cemeteries: A prevalently burial system cemetery (burial of the bodies in the ground, generally in wooden casks) is comparable, due to the effects on the environment, to an organic material discharge site, but which does not have protection membranes underground and therefore with the possibility of dilution and dispersion of the organic material in the 
ground and in the surrounding water tables (Personal communication from the person in charge of Federgasacqua SEFIT (Italy) and President of the Work Committee for the Cemeteries and Crematoriums of the FEFS (European Federation of Funeral Services)).

The decomposition of bodies determines potential chemical pollutants, of which compounds of carbon, ammonia, chlorides, sulphites, sodium and potassium prevail. For this reason, the weights relative to the different factors have always been assessed as elevated and are only differentiated according to:

- The potential polluting load $(\mathrm{C})$, in relation to the quantity of water (washing away effect) in contact with the body

- The frequency (D), which can be higher or lower, in relation to the state of conservation of the coffin

Waste disposal sites: Solid urban waste and all the different types of waste from human activities (construction debris, industrial scraps...) are deposed off in waste disposal sites. The national law Legislative Decree 36/2003 acknowledges European Directive 99/31/EC, which foresees three different types of waste disposal site:

- $\quad$ Sites for the disposal of inert material

- Sites for the disposal of non hazardous material (including Solid Urban Waste-SUW)

- $\quad$ Sites for the disposal of hazardous waste material (including ash and scraps from incinerators)

The national law also defines a surveillance and monitoring plan with the necessary chemical, chemicalphysical, hydrogeological, meteorology climatic and topographic parameters that have to be determined periodically according to an established measuring frequency. Unfortunately, these rules are not always respected, as is the case, for example, of waste disposal sites that have not been built or maintained according to regulations and it is for this reason that the assigned parameters express the maximum hazard risk (parameters A, B, C and D) and the minimum control (parameters $\mathrm{E}$ and $\mathrm{F}$ ).

Service stations, fuel storage sites: These two categories are considered as HCs because of the chemical-physical characteristics of the hydrocarbons that are stored. Furthermore, the fossil fuels are often stored in tanks below the ground level and, in the case of breakage of the tanks, it is particularly easy for spillage to occur.

On the basis of data collected over the last 40-50 years by Public Administrations, it is possible to calculate the $\mathrm{C}, \mathrm{D}$ and $\mathrm{F}$ parameters of the individual activities in a different way, thus:
Table 5: Weight class in relation to the $\mathrm{MC}_{\mathrm{S}}$ of the stored hydrocarbons

\begin{tabular}{ll}
\hline Stored $\mathrm{MC}_{\mathrm{S}}$ & Weight class \\
\hline $0-30$ & 1 \\
$31-50$ & 2 \\
$51-200$ & 3 \\
\hline
\end{tabular}

Table 6: Weight class in relation to the burial date

\begin{tabular}{lll}
\hline Years & D & F \\
& Weight class & Weight class \\
\hline $60-{ }^{\prime} 80$ & 3 & 3 \\
$81-2000$ & 1 & 2 \\
$2001-2008$ & 1 & 1 \\
\hline
\end{tabular}

- $\quad$ For the potential polluting load (C), the number of tanks encountered in the activity at risk and the total quantity of fossil fuel stored were taken into account and 3 weight classes were identified (Table 5)

- For the frequency (D) and the preventive control degree $(\mathrm{F})$, the data concerning when the tanks were buried were taken into account and were divided into 3 weight classes (Table 6)

In the case where these data concerning the activities were missing, the critical scenario was described and the maximum weight was given to all the factors, while a mean weight was identified for the ordinary scenario.

Hospitals, clinical and veterinary clinics: The hospital, veterinary and laboratory clinics were grouped together as the type of action is the same: all the places where surgical operations and specialist visits are carried out are considered HCs as they use contrast liquids and chemical and medicinal substances in environments that are often loaded with bacteria and viruses. Furthermore, the tanks where the different chemical and toxic substances are stored should also be considered HCs. For this reason, the different parameters vary according to:

- $\quad$ The potential polluting load (C), which can vary in relation to the operating level of the activity and to the different lengths of the pollutant spillage phenomenon

- The frequency (D), which can change in relation to the probability that an accident could occur or not and if this presupposes a constant duration during the year

- The preventive control degree $(\mathrm{F})$, in relation to whether the activity is carried out in suitable premises and whether a continuous monitoring of the activity is foreseen

Laundries and dry-cleaners: The laundry category is divided into two scenarios in relation to: 
- The potential concentration (B), in relation to the different detergents and the quantities that are used

- The polluting load potential (C), in relation to the operating level of the activity

- The frequency (D), relative to the possibility or not of an accident occurring

- The preventive control degree $(\mathrm{F})$, on the basis of the structure in which the activity is carried out and whether it is subject to monitoring

Dry-cleaners are considered HCs because of their working cycle. Organic solvents or chlorinated organic solvents and substances or preparations, classified according to the Legislative Decree of 3 February 1977, no 52 as carcinogenic, mutagenic or toxic for reproduction, can be utilized during the washing processes.

It was considered advisable to divide all the factors into two scenarios, with the exception of potential toxicity (parameter A) which was kept constant at the maximum value.

Metal work firms: This category is considered a $\mathrm{HC}$ due to the substances that are used for the manufacturing process. It is in fact known that iron and steel manufacturing processes produce polluting substances which are often dispersed in both groundwater and aquifers and which alter their natural equilibrium. For these reasons, a maximum weight was given to all the factors in both scenarios, with the exception of:

- The potential polluting load $(\mathrm{C})$, in relation to the operating level of the activity

- The potential frequency (D), in relation to the probability of whether an accident occurs or not

Water and urban land management:

Study area 1: The Autonomous Aosta Valley region:

The territory on which the first analysis was conducted includes a part of the Aosta Valley, a region that borders on France, Switzerland and the Piedmont region. The studied area is in the municipality of Aosta, a city located on the mid-plain of the Aosta Valley.

From a geological point of view ${ }^{[5]}$, the Aosta Valley is part of the alpine mountain chain known as the Western Alps.

From the investigations that were carried out, it emerged that the postglacial filling of the Aosta valley plain houses two aquifer systems: an unconfined one and a confined one.
An unconfined aquifer can be found above Aosta in gravelly sediments, which guarantee protection of the aquifer water from any possible pollution of bacterial origin. At least two aquifers have been identified below Aosta: A surface phreatic one with a depth of $20-37 \mathrm{~m}$ and another deeper confined one, which is sometimes under pressure, of a depth of $5 \mathrm{~m}$.

The water flow of the groundwater is generally directed from West to East, parallel to both the rocky slope that borders the aquifer on the North and to the Dora Baltea River. The hydraulic gradient varies from a maximum of $8 \%$, in the sector above, to a minimum of $4 \%$ in the sector below.

As far as the depth-to-water is concerned, the lowest values, of between 0 and $5 \mathrm{~m}$, are encountered in the sector close to the Dora Baltea riverbed. Going towards the city of Aosta, the depth-to-water of the unconfined aquifer varies from values of $10-20 \mathrm{~m}$, except for in the historical centre where the values exceed $20 \mathrm{~m}$ and even reach a maximum of $32 \mathrm{~m}$ close to the Roman Amphitheatre.

From the settlement point of view, the area is made up of an urban fabric that is represented by the city of Aosta, a large metallurgic industrial area (to the south of Aosta) and by different outlying inhabited centers which, in recent years, have been subjected to a deurbanization phenomenon in favor of the main town.

Study area 2: The Veneto Region: The territory on which the second analysis was conducted is located in the centre of the Veneto Region, on the border between the Provinces of Padua and Vincenza and it falls inside three municipalities: Tezze sul Brenta, Cittadella and Fontaniva.

The origin of the Veneta Plain dates back to the end of the Tertiary era, but it was only at the beginning of the Quaternary era that the vast depression was filled by a progressive accumulation of alluvial deposits belonging to the large fluvial systems, spaced out by sediments derived from the various marine transgression stages. The studied area is in the High Veneta Plain and, according to the "Classification of the Italian Soils in a 1:25.000 scale" (The World Reference Base for Soil Resources (FAO, 1998) was used as the classification system.), it is part of the AA2 Classification "Soil on a fluvial-glacial fan with few signs of relict hydrography formed of strongly or extremely calcareous gravelly sands".

Geomorphologically, the territory is characterized by the presence of the Brenta river which flows along one of the sides of the area and by an area of resurgence (A resurgence is a spring of fresh water, typical of the Padana plain) located to the South. 
As far as the hydrogeological aspect is concerned, one single large aquifer, with some clay lenses that become different once the resurgence zone is reached at Fontaniva, can be found that goes from north to south.

In the department to the north of Cittadella and Fontaniva, the phreatic surface deteriorates in a homogeneous way, according to an almost constant dip: the mean local hydraulic gradient is equal to $1-3 \%$, with higher values near the Brenta fluvial bar.

The maximum hydraulic gradient is found just south of the town of Bassano del Grappa $(2-2.5 \%$ and it is here that the greatest velocity of the groundwater flow is encountered (40-60 m day ${ }^{-1}$ ); the mean velocity of $10-15 \mathrm{~m} / \mathrm{d}$ is found in the Cittadellese area.

The mean depth-to-water of the aquifer is about $20 \mathrm{~m}: 28 \mathrm{~m}$ in the municipality of Tezze sul Brenta and this descends to $6 \mathrm{~m}$ in the municipality of Cittadella. The Fontaniva resurgence area, following the removal of gravel from a height of $7 \mathrm{~m}$ from the riverbed, which is not consistent with the structure and equilibrium of the aquifer, induced a change in the point of emergence of the water of the municipality, from north to south.

From the settlement point of view, a sprawl (An English term that indicates a rapid and unorganised growth of a metropolitan area, a phenomenon which, in most cases, occurs most frequently in the suburban areas, given the description of area of recent expansion and subject to continuous change. The term used in Italy to describe this phenomenon is "città diffusa" (diffused city)) model can be found with scattered houses and this is alternated, without any previous planning, with farm areas and industries.

\section{RESULTS}

Study area 1: The autonomous Aosta Valley region: In order to apply the Holman method, it was first necessary to identify the perimeter of the study area. A Databank was therefore constructed and this proved to be a particularly costly operation, in terms of time and complicated, considering the fact there was no unified regional territorial information system (Fig. 2).

The information useful for the analyses was obtained from national, regional and municipality public organizations.

The Databank, which was implemented in a GIS, is composed of:

- The cartography of the study area: CTR 5.000 raster, orthophotos and georeferenced files relative to the hydrography, to the borders of the municipality of Aosta, to the street numbers and to the main and secondary traffic infrastructures

- The types of activity at risk to pollution of the GWR: Car repair/body shops, car washes, dairies, typing agencies, fuel storage sites, buried fossil fuel tanks (blocks of flats and activities), service stations, electromechanical firms, metal work firms, laundries and dry-cleaners, hospitals, clinical and veterinary laboratories, cemeteries

- The wells in the study area, which have been identified with a univocal code

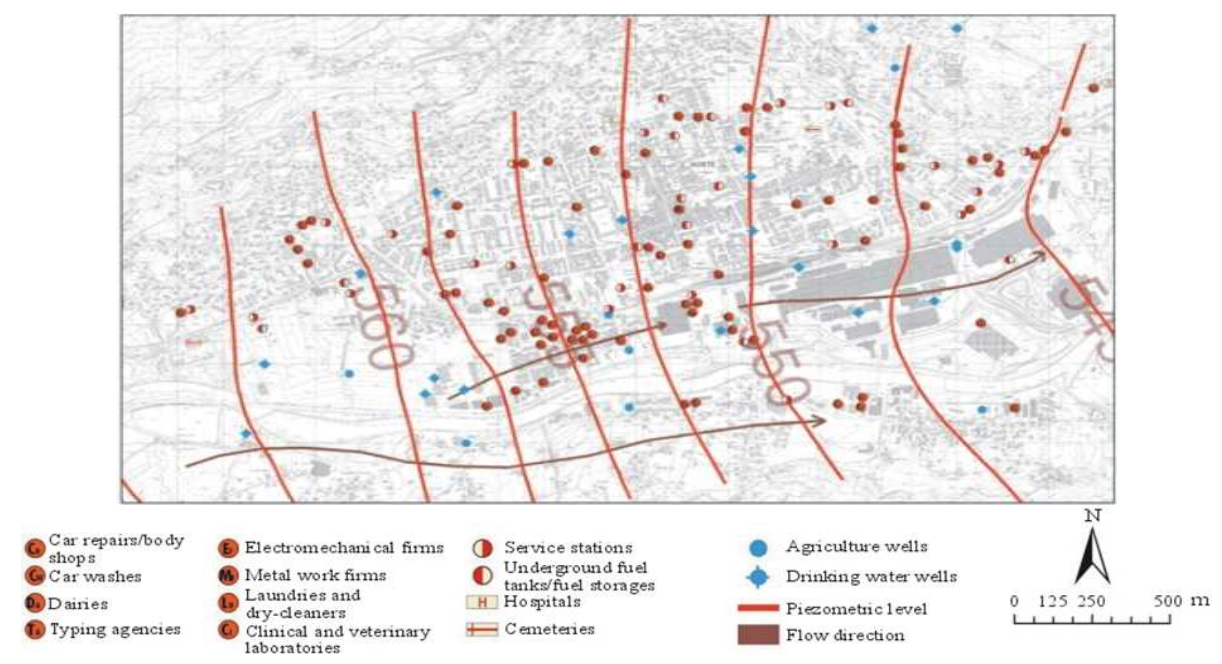

Fig. 2: Application of the Holman method 
Am. J. Environ. Sci., 5 (6): 727-739, 2009

Table 7: Activity types and the relative release areas

\begin{tabular}{llll}
\hline Type of activity & Area (ha) & Type of activity & Area (ha) \\
\hline Car repairs/body shops & 0.050 & Electromechanical firms & 0.050 \\
Car washes & 0.040 & Metal work firms & 0.020 \\
Dairies & 0.030 & Laundries and dry-cleaners & 0.020 \\
Typing agencies & 0.008 & Hospitals & 1.300 \\
Fuel storages & 0.030 & Clinical and veterinary laboratories & 0.035 \\
Underground fuel tanks (apartment blocks and businesses) & 0.100 & Cemeteries & 2.600 \\
Service stations & 0.100 & & \\
\hline
\end{tabular}

Table 8: Example of an $\mathrm{HI}$ attributed to laundry and dry cleaner activities

\begin{tabular}{|c|c|c|c|c|}
\hline \multicolumn{3}{|c|}{ High HI = 729} & \multirow[t]{2}{*}{ Risk } & \multirow[t]{2}{*}{ Low $\mathrm{HI}=72$} \\
\hline & \multicolumn{2}{|c|}{ Type of activity: Laundry dry-cleaners } & & \\
\hline & Code & Description & & Motivation \\
\hline \multirow{4}{*}{$\begin{array}{l}\text { Hazard } \\
\text { factors }\end{array}$} & A & Potential toxicity of the discharged pollutants: & 3 & Toxic chemicals \\
\hline & B & Potential concentration of the discharged pollutants: & $\begin{array}{l}3 \\
2\end{array}$ & $\begin{array}{l}\text { The concentration of the pollutants can be elevated or } \\
\text { modest according to the detergents used }\end{array}$ \\
\hline & $\mathrm{C}$ & Potential polluting load: & $\begin{array}{l}3 \\
2\end{array}$ & $\begin{array}{l}\text { The polluting load can be considered elevated or medium } \\
\text { in relation to the activity's operating level }\end{array}$ \\
\hline & $\mathrm{D}$ & Potential frequency of the polluting discharge: & $\begin{array}{l}3 \\
1\end{array}$ & $\begin{array}{l}\text { The frequency can change depending on the probability of } \\
\text { an accident happening or not }\end{array}$ \\
\hline \multirow[t]{3}{*}{$\begin{array}{l}\text { Control } \\
\text { factors }\end{array}$} & $\mathrm{E}$ & Degree of natural protection: & 1 & $\begin{array}{l}\text { It is always elevated since, should a spillage occur, this } \\
\text { would be within the premises, with a nil or almost nil level } \\
\text { of pollution risk. It would be a different case if the spillage } \\
\text { occurred in the store where the pollutant is kept }\end{array}$ \\
\hline & $\mathrm{F}$ & $\begin{array}{l}\text { Degree of preventive control of the centre subject } \\
\text { to hazard }\end{array}$ & $\begin{array}{l}3 \\
2\end{array}$ & $\begin{array}{l}\text { Depending on the type of premises in which the activity } \\
\text { is being carried out, it could be poor or modest }\end{array}$ \\
\hline & $\mathrm{G}$ & Relative distance to the closest polluting subject: & 3 & Parameter calculated per single activity \\
\hline
\end{tabular}

Table 9: HI and THI values calculated for each type of activity

\begin{tabular}{|c|c|c|c|c|}
\hline \multirow[b]{3}{*}{ Type of activity } & \multicolumn{3}{|c|}{ Values } & \\
\hline & \multicolumn{2}{|c|}{ Ordinary scenario } & \multicolumn{2}{|c|}{ Critical scenario } \\
\hline & HI & THI & $\mathrm{HI}$ & THI \\
\hline Car repairs/body shops & 51 & 0.09180 & 459 & 0.82620 \\
\hline Car washes & 72 & 0.01100 & 486 & 0.07770 \\
\hline Dairies & 72 & 0.00216 & 324 & 0.00972 \\
\hline Typing agencies & 18 & 0.00028 & 324 & 0.00500 \\
\hline Fuel storages & 990 & 0.89100 & 1485 & 1.33650 \\
\hline Underground fuel tanks (apartment blocks and businesses) & 571 & 0.62820 & 842 & 0.92610 \\
\hline Service stations & 709 & 4.89240 & 1063 & 7.33860 \\
\hline Electromechanical firms & 22 & 0.00225 & 270 & 0.02700 \\
\hline Metal work firms & 54 & 0.00108 & 324 & 0.00648 \\
\hline Laundries and dry-cleaners & 72 & 0.03456 & 729 & 0.34992 \\
\hline Hospitals & 54 & 0.14040 & 324 & 0.84240 \\
\hline Clinical and veterinary laboratories & 54 & 0.00945 & 324 & 0.05670 \\
\hline
\end{tabular}

The weights relative to the HFIs and the CFIs (as shown in Table 1 and 2) of the aforementioned different types of activity at risk were assigned to calculate the HIs and the THIs, hypothesizing their relative release surfaces (Table 7), which were calculated as follows:

- For the activities that present a particularly large surface, such as hospitals and cemeteries, the actual occupied surface area identified on the CTR

- For the activities that present a relatively modest occupied surface area (such as, for example, laundries and carpentry workshops), a mean of the areas occupied by each single activity of each type was used in order to standardize the data

In the Holman analysis, the "probability factor" has a particularly elevated weight. It proved necessary, in the calculation of the weights, to hypothesize both an accidental risk and an uncontrolled spillage (in time and quantity) during the development of the activity. Two reference scenarios were therefore elaborated, a more "critical" one and an "ordinary" one and different weights were assigned to the single factors that make up the HI.

The calculation that was carried out for the laundry activity is shown in Table 8 as an example. 
The application of the Holman model leads to three distinct results, in relation to the two scenarios that have been formulated (the results in Table 9):

- There are activity categories that show a Low HI in both scenarios

These activities include carwashes, typing agencies, garages and bodyshops, hospital structures, clinical (veterinary) laboratories and metalworks

- The laundries and cemeteries, instead, only show a Medium HI in the scenario defined "critical", but in the "ordinary" scenario they have a Low HI

- The fuel storage sites, the buried tanks and the service stations all show a Medium or Elevated HI in both scenarios

The application of the Holman method therefore does not show any activities that are a particular risk of pollution, except for the activities in point 3 .

Thanks to the results that were obtained, it is possible to derive two important pieces of planning information:

- To understand which activity categories are the greatest risk of pollution (thanks to the THI value)

- To understand, within the same group, which activities are more risky than the others (HI value). An example is given in order to explain these points more clearly: considering the following service stations Table 10, it is possible to see which activities compete to be the greatest risk for the aquifer. For example, petrol station 3 has a very high $\mathrm{HI}$ compared to station 12

In fact, parameter $\mathrm{C}$ (potential polluting load) is very high for both activities while parameters $D$ and $F$ show a substantial difference, given that the two tanks were buried in very different periods: the first in the sixties-eighties and the second at the end of the nineties. This means that the frequency of the discharge is higher for one activity than the other because of obsolescence.

Table 10: Comparison of fuel service stations

\begin{tabular}{llllllllllr}
\hline Type of activity & A & B & C & D & E & F & G & HFI & CFI & HI \\
\hline Service station 1 & 3 & 3 & 3 & 1 & 3 & 2 & 3 & 27 & 18 & 486 \\
Service station 2 & 3 & 3 & 1 & 3 & 3 & 3 & 3 & 27 & 27 & 729 \\
Service station 3 & 3 & 3 & 3 & 3 & 3 & 3 & 3 & 81 & 27 & 2187 \\
Service station 4 & 3 & 3 & 2 & 3 & 3 & 3 & 3 & 54 & 27 & 1458 \\
Service station 5 & 3 & 3 & 1 & 3 & 3 & 3 & 3 & 27 & 27 & 729 \\
Service station 6 & 3 & 3 & 2 & 3 & 3 & 3 & 3 & 54 & 27 & 1458 \\
Service station 7 & 3 & 3 & 3 & 3 & 3 & 3 & 3 & 81 & 27 & 2187 \\
Service station 8 & 3 & 3 & 2 & 1 & 3 & 2 & 3 & 18 & 18 & 324 \\
Service station 9 & 3 & 3 & 2 & 3 & 3 & 3 & 3 & 54 & 27 & 1458 \\
Service station 10 & 3 & 3 & 2 & 3 & 3 & 3 & 3 & 54 & 27 & 1458 \\
Service station 11 & 3 & 3 & 2 & 1 & 3 & 2 & 3 & 18 & 18 & 324 \\
Service station 12 & 3 & 3 & 3 & 1 & 3 & 2 & 2 & 27 & 12 & 324 \\
Service station 13 & 3 & 3 & 2 & 3 & 3 & 3 & 2 & 54 & 18 & 972 \\
Service station 14 & 3 & 3 & 3 & 3 & 3 & 3 & 3 & 81 & 27 & 2187 \\
\hline
\end{tabular}

As a consequence, in the case in which the quality of this water results to be poor in an analysis, because of pollutants (hydrocarbons), the environmental experts would be likely to carry out further analyses at the site that is presumed to be the source of the pollution.

If we analyze the THI parameter, it is also possible to understand which activities are the greatest risk by relating them to the territory in which they are located. Again in this case, there is a net difference between the different groups of classified activities. Practically all the "commercial or craftsman" activities show an THI that does not surpass 1 (considering the critical scenario), because the pollutant release areas are relatively modest. The situation indicated for the fuel deposits, the service stations and the cemeteries, which have a release area of between 0.03 ha and 2.6 ha, is instead different and the risk (THI) is defined as:

- 1.33 for the fuel deposit sites (release area of 0.03 )

- 7.33 for the service stations (release area of 0.1)

- 5.05 for the cemeteries (release area of 2.6)

The service stations, being particularly numerous and often having obsolete tanks, are the activities that result to be the greatest risk; the cemeteries, though showing a much lower HI value than the fuel deposit sites (potentially medium impact), but having a particularly extended release surface, are considered an activity with a relevant risk of pollution (THI value).

One final consideration is however necessary. Although these activities all show an elevated risk, the service stations should clearly be considered the activities with the greatest risk as they define a network of HCs spread throughout the territory; the cemeteries, on the other hand, are sources of a dispersion in the aquifer which, though territorial, can be considered point sources if analyzed at a territorial level.

Study area 2: The Veneto region: The first operation necessary to apply the Holman method to the municipalities of Tezze sul Brenta, Cittadella and Fontaniva (Fig. 3) was that of establishing which categories of activities could be considered HCs and therefore to determine, in a more or less decisive way, the pollution of the groundwater in the case of spillage, considering them one at a time and then taken together.

The choice of the activities to which the Holman method should be applied was based on a series of operations. Initially, the numerous activities at risk were identified, using the table of the 95 categories of activities already available from the literature ${ }^{[12]}$. Once the remaining activities useful for the analysis had been 


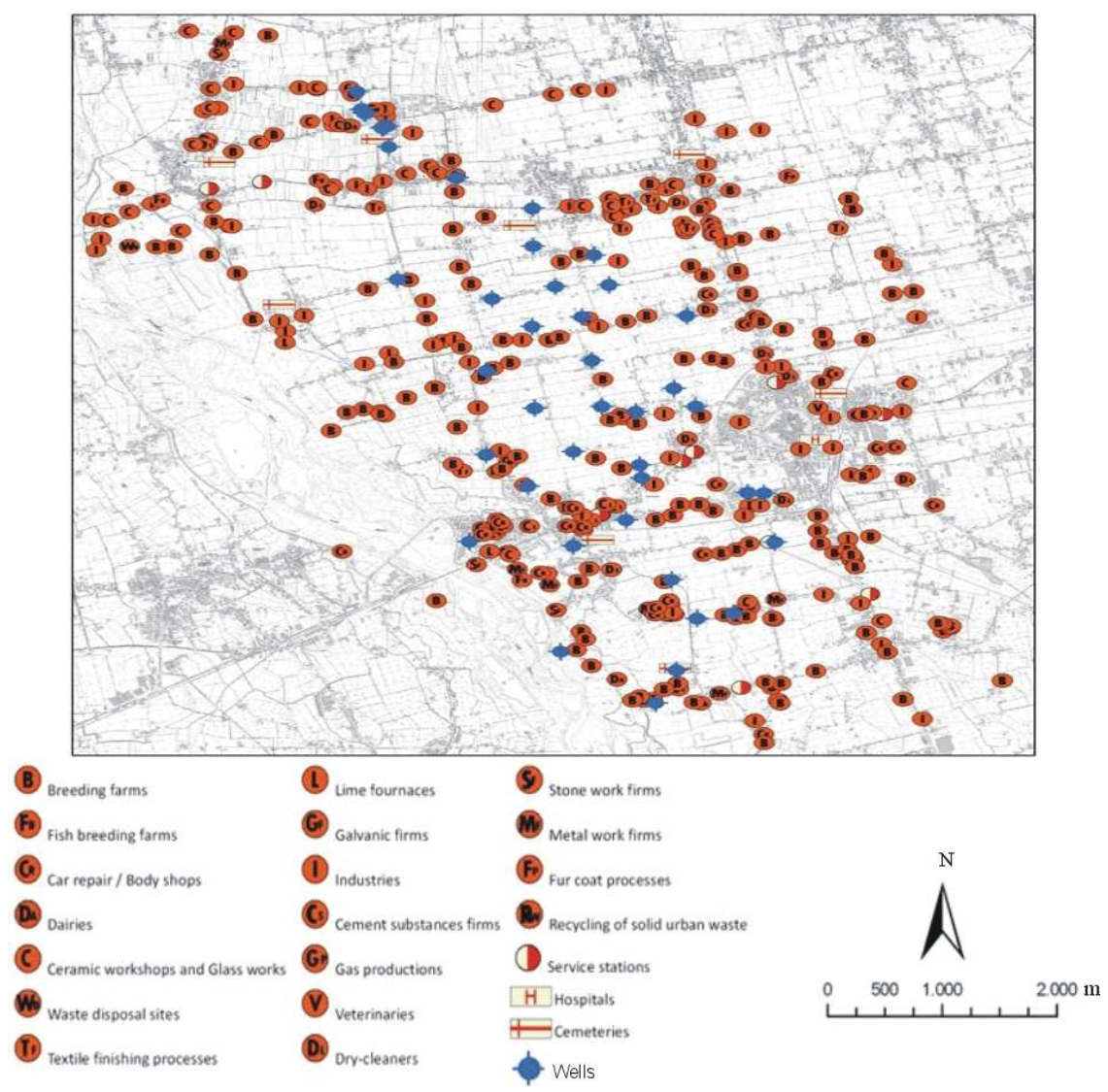

Fig. 3: Application of the Holman method

identified, the complete list of activities at risk to pollution on the studied territory was drawn up. This list included the following categories: Breeding farms, fish breeding farms, car repairs/body shops, dairies, ceramic workshops and glass works, cemeteries, waste disposal sites, textile finishing processes, lime furnaces, galvanic firms, industries, cement substances firms, gas productions, service stations, hospitals and veterinary clinics, dry-cleaners, stone works, metal work firms, fur coat processes, recycling of solid urban waste and cotton productions.

Different weights were assigned to evaluate the potential impact of the HCs on the hazard factors (A, $\mathrm{B}, \mathrm{C}$ and $\mathrm{D})$ and on the control factors (E and F) of each category, considering two different scenarios: The first, called "ordinary scenario", for when the spillage level does not reach the maximum hazard; the second, defined "critical scenario", in which many parameters can reach a level that can be considered alarming. Finally, the parameter $G$ was calculated through an operation that measured the distance between the activity at risk and the well closest to it.

The potential impact shown in Table 3 was identified for each $\mathrm{HC}$, according to the results of the HI.

In this way a census card was elaborated for each single activity, as shown in Table 4.

A database was then set up and all the HCs and wells were georeferenced on a CTR cartographic basis, thanks to the use of a GIS.

From the analyses that were conducted (Table 11), it can be stated that the "ordinary scenario" indicates a low level of HI, with the exception of:

- The galvanic firms category and that of the service stations, which show a medium level

- The waste disposal sites category, which shows an elevated level

The industries activities show a low risk, since no particularly hazardous situations are considered, although they are considered in the second scenario. 
Am. J. Environ. Sci., 5 (6): 727-739, 2009

Table 11: HI and THI values calculated for each type of activity

\begin{tabular}{|c|c|c|c|c|}
\hline \multirow[b]{3}{*}{ Type of activity } & \multicolumn{4}{|l|}{ Values } \\
\hline & \multicolumn{2}{|c|}{ Ordinary scenario } & \multicolumn{2}{|c|}{ Critical scenario } \\
\hline & HI & THI & $\mathrm{HI}$ & THI \\
\hline Breeding farms & 38.38 & 0.257 & 344.90 & 2.311 \\
\hline Fish breeding farms & 304.00 & 0.912 & 1602.00 & 4.806 \\
\hline Car repairs/body shops & 10.20 & 0.006 & 184.00 & 0.104 \\
\hline Dairies & 37.30 & 0.009 & 504.00 & 0.125 \\
\hline Ceramic workshops and glass works & 213.15 & 4.050 & 690.63 & 13.122 \\
\hline Cemeteries & 277.00 & 5.762 & 1215.00 & 25.272 \\
\hline Waste disposal sites & 1458.00 & 21.870 & 2187.00 & 32.805 \\
\hline Textile finishing processes & 300.00 & 1.350 & 1350.00 & 6.075 \\
\hline Lime furnaces & 48.00 & 0.014 & 324.00 & 0.097 \\
\hline Galvanic firms & 972.00 & 0.729 & 1944.00 & 1.458 \\
\hline Industries & 164.84 & 12.528 & 1128.70 & 85.781 \\
\hline Cement substances firms & 205.70 & 0.069 & 2082.80 & 0.700 \\
\hline Gas productions & 96.00 & 0.024 & 729.00 & 0.182 \\
\hline Service stations & 604.80 & 0.605 & 1360.80 & 1.361 \\
\hline Hospitals and veterinary clinics & 76.00 & 0.608 & 729.00 & 5.832 \\
\hline Dry-cleaners & 29.60 & 0.026 & 800.50 & 0.708 \\
\hline Stone work firms & 22.40 & 0.029 & 576.00 & 0.749 \\
\hline Metal work firms & 22.00 & 0.006 & 297.00 & 0.083 \\
\hline Fur coat processes & 324.00 & 0.037 & 972.00 & 0.111 \\
\hline Recycling of solid urban waste & 96.00 & 0.036 & 648.00 & 0.246 \\
\hline Cotton productions & 24.00 & 0.029 & 216.00 & 0.259 \\
\hline \multicolumn{5}{|c|}{ Table 12: Activity types and the relative release areas } \\
\hline Type of activity & Area (ha) & \multicolumn{2}{|c|}{ Type of activity } & Area (ha) \\
\hline Breeding farms & 0.05 & \multicolumn{2}{|c|}{ Gas productions } & 0.25 \\
\hline Fish breeding farms & 1.00 & \multicolumn{2}{|c|}{ Service stations } & 0.10 \\
\hline Car repairs/body shops & 0.02 & \multicolumn{2}{|c|}{ Hospitals and veterinary clinics } & 2.00 \\
\hline Dairies & 0.08 & \multicolumn{2}{|c|}{ Dry-cleaners } & 0.05 \\
\hline Ceramic workshops and glass works & 0.05 & \multicolumn{2}{|c|}{ Stone work firms } & 0.26 \\
\hline Cemeteries & 2.60 & \multicolumn{2}{|c|}{ Metal work firms } & 0.04 \\
\hline Waste disposal sites & 150 & \multicolumn{2}{|c|}{ Fur coat processes } & 0.06 \\
\hline Textile finishing processes & 0.50 & \multicolumn{2}{|c|}{ Recycling of solid urban waste } & 0.38 \\
\hline Lime furnaces & 0.15 & \multicolumn{2}{|c|}{ Galvanic firms } & 0.25 \\
\hline Industries & 1.00 & \multirow{2}{*}{\multicolumn{2}{|c|}{ Cement substances firms }} & 0.05 \\
\hline Cotton productions & 1.20 & & & \\
\hline
\end{tabular}

In the "critical scenario", instead, different degrees of hazard can be noted:

- The breeding farms, car repairs/body shops, dairies, lime furnaces, metal work firms and cotton productions categories all remain at a low level and unchanged from the ordinary scenario

- The fish breeding farms, the ceramic workshops and glass works, the gas productions, the hospital and veterinary clinics, the dry-cleaners, the stone work firms, the fur coat processing and the recycling of solid urban waste activity categories are instead of a medium level

- The cemeteries, textile finishing processes, industries and service stations categories are of an elevated level

- The waste disposal sites, galvanic firms and cement substances firms categories are all of a very elevated level
After having determined the release area for each activity category (Table 12), the value of the THI was determined: From an analysis of the obtained results, it can be seen how three categories of risk activities emerge:

- First, the industries category, which has a value of 12,528 in the ordinary scenario has a value of 85,781 in the critical scenario; this particularly elevated value derives from the fact that there is such a large number of activities that this number creates a network at a territorial level which is a risk of pollution, also considering that each single industry should be considered an aggregate of the HC. Furthermore, the waste disposal sites are also present which have a value of 21,870 in the ordinary scenario and 32,805 in the critical scenario. As only one waste disposal sites can be found in the studied area, the THI values (that territorialize the analysis) are coherent with the 
Am. J. Environ. Sci., 5 (6): 727-739, 2009

hypothesized potential impact values (very elevated impact)

- The second category of activities is represented by the cemeteries, which show a value of 5,762 in the ordinary scenario and of 25,272 in the critical scenario; these values are coherent with those calculated with respect to the potential impact. Subsequently, we find the ceramic workshops and glass works activities, which show a value of 4,050 in the ordinary scenario and of 13,122 in the critical scenario; as there is a large number of activities (38), this category is considered a risk, even though it has a medium potential impact. Finally, different activities have been identified (breeding farms, fish breeding farms, textile finishing processes, galvanic firms, service stations, hospital and veterinary clinics) which show THI values of between 1,361 and 6,075; these activities could be a risk of pollution in relation to an elevated potential impact value or to a high presence on the studied territory

- The remaining activities, which show an THI value below 1 in both scenarios, are found in the third category

\section{DISCUSSION}

From this work appears, with increasing importance, an integrated approach to the planning and management of the territory which consider all the components associated, both natural and human induced $^{[4,7,11]}$. Consequently the "territorial planner" represents the person who has the capacity of drawing the right considerations from the results of the technical analyses so that strength and weakness points analyzed about the territory can be found.

In this context, the Holman method is particularly useful for a first analysis, to use in emergency situations, for the evaluation of the activities that are possibly the greatest pollution risk for the GWR throughout the territory. If, during the chemical analyses, a well results to be polluted, it would be easy to assume where the source of this pollution comes from.

In this study, the Holman method was applied to two remarkably different areas, both because of their hydrogeological aspects and because of their urban aspects, utilizing a common approach for the construction and development of the project:

- The first study area, in the Aosta Valley, is a typical pre-mountainous area that has the settlement fabric characteristics of a medium-small town (Aosta); there is an alternation of buildings of commercial and craftsman activities (Fig. 4) while, towards the outskirts of the city, subsistence farming and breeding activities can be encountered and sometimes small industrial activities. The only exception is that of a large metallurgical industry which extends towards the southern border of the city

- The second study area, which includes three municipalities in the Veneto Region (Tezze sul Brenta, Cittadella and Fontaniva), is located on a plain and it has a high number of industrial activities with an elevated risk of pollution and these alternate with intensive agricultural activities (Fig. 5).

Although there are many local organizations in Italy that are in charge of analysis and monitoring, there is frequently no contact between them and it therefore occurs that the data in their hands are often contradictory or not updated, unusable or even obsolete. It is therefore necessary to consider the importance of constructing a standardized Geographical Information System (GIS) that could easily be updated through the use of census cards, in order to be able to collect both those activities that are at risk of polluting the surface and groundwater resources and also the tapping wells of the aqueduct network used for human supply.

Congruent results have emerged from the conducted analyses concerning the levels of risk of the different activities, but some discrepancies have emerged, which are sometimes quite marked, between the two scenarios. In fact, even though the parameters relative to the hazard and control factors are naturally the same for both analyses, some have resulted to be too specific and difficult to quantify in an objective manner (in particular for the hazard factors) and it was therefore necessary to construct two hypothetical risk scenarios to describe all the possible spillage situations. The first study area, relative to the municipality of Aosta, does not show any particular situation at risk, with the exception of the activities connected to the laundries and dry-cleaners, all those that deal with hydrocarbons and cemeteries; in this way, it is possible to arrange cautionary measures or monitoring, utilizing this particular method, for the case of a possible risk of pollutant spillage.

The second analysis, relative to the municipalities in the Veneto region, concern a territory at a high risk of pollution for the GWR, because of the numerous economic activities at installed risk. Many craftsman and industrial activities relative to the production and transformation of gas, to galvanic processing, to cement processing, to fish breeding farms and some cemeteries, service stations and a waste disposal site can be found on the territory. 


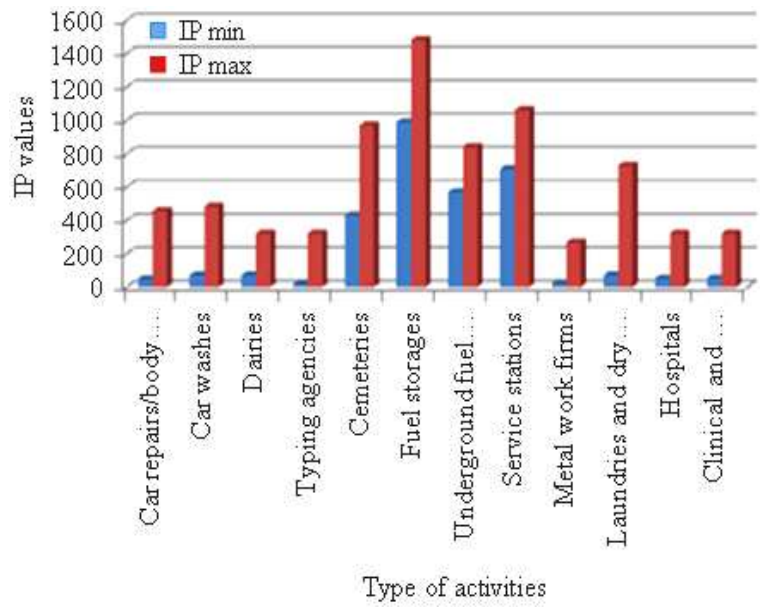

Fig. 4: HI values calculated for each type of activity

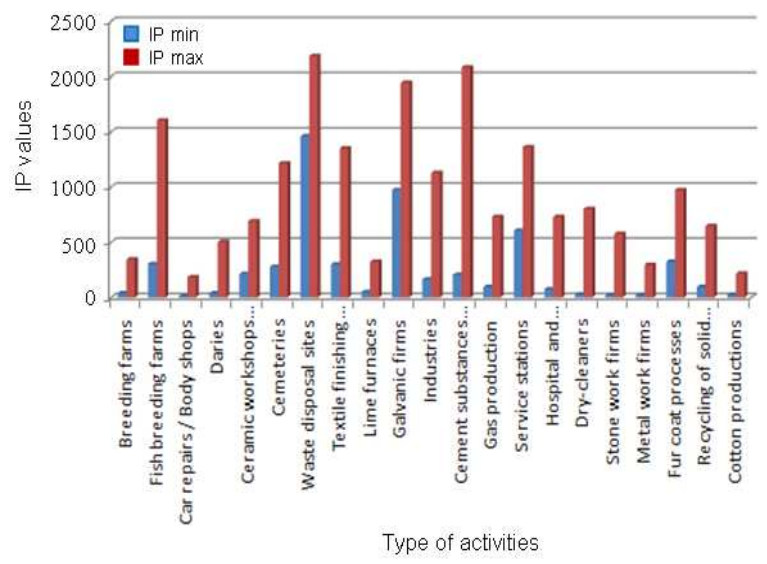

Fig. 5: HI values calculated for each type of activity

It is worthwhile noting how the results of the application of the Holman method can be different, for the same type of activity, in relation to the subjectivity of whoever carries out the analyses. The two study areas were analyzed using a common procedure in the analysis preparation stage, but without a standard determination of the weight to attribute to each single risk and control factor for each type of activity. Two similar analyses emerged, with respect to the categories considered at risk, but which were very different as far as the weight attributed to the single factors and therefore to the potential impact that is derived from them is concerned.

In particular it emerged, in the second analysis, how higher weights were constantly attributed to all the different parameters in such a way that HI values above 2000 were justifiable for both the waste disposal sites and the cement processing activities.

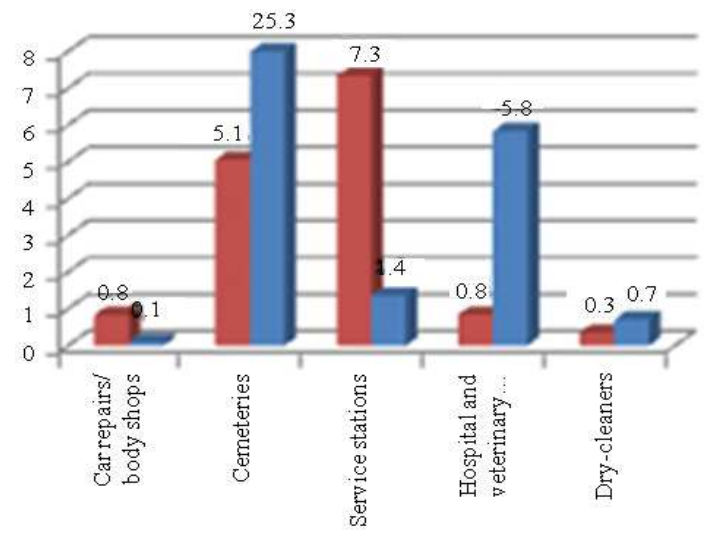

Fig. 6: Comparison between the two THI study areas

In this way, even the THI (for the activities that are present in about the same number and for which the same release area has been calculated) results to have a clearly higher value; this is the case, for example, of the cemeteries and of the hospital and veterinary surgery categories.

If we instead consider the service stations, it is possible to observe that the THI value is clearly higher in the first analysis, even though the HI value (calculated in the critical scenario) is clearly lower (Fig 6); this is due to the fact that, even with the same calculated release surface $(0.1 \mathrm{ha})$, the number of service stations is clearly higher in the first analysis and is so high that it can be considered a network of activities with a risk of polluting.

With reference to what has been presented in this article, it is possible to state that the Holman method is particularly important when it is necessary to assume imminent decisions, when faced with the possible dispersion of pollutants in an aquifer ${ }^{[6,9]}$. However, it has also emerged from this work that its reliability is closely connected to two different data availability conditions:

- In the case of limited economic resources, which is often the case for operators in Public Organizations, there is some question as to whether the data available for the technicians are sufficient to conduct analyses in an objective technical-scientific way; as a consequence, the analyses could result to be approximate with a rather high margin of error

- In the presence of an adequate analysis and monitoring activity, carried out above all through census and using specific cards of all the HCs and of all the tapping wells in the area, it is instead possible to attribute a correct and objective weight to the different hazard and control factors in such a 
way as to render the analyses affordable in an administrative-territorial context

In this second case, the economic resources used to develop the Holman method, which might seem unjustifiable considering the efficacy of this method, offer the basis for subsequent, complete and more reliable investigations. In fact, all the investigations of a territorial nature that also extend the analyses to consider the hydrogeological aspect of the studied territory, are founded on the detailed knowledge of all the HCs and the treated substances that can be the cause of pollution for GWR.

\section{CONCLUSION}

Only when knowledge of this type is available will it be possible, from the territorial government strategic point of view, to take appropriate decisions on the granting, or refusal, of permission to build or insert activities that could present an elevated pollution risk for GWR.

\section{ACKNOWLEDGEMENT}

A grant issued by the European Social Fund (FSE) was used to carry out part of this study.

\section{REFERENCES}

1. Civita, M. and A. Zavatti, 2006. Un manuale per 1' analisi di sito e la valutazione del rischio di inquinamento. A manual for analysis site and the evaluation of pollution hazard. Quaderni e Tecniche di Protezione Ambientale, 80, Pitagora Editrice, Bologna, ISBN: 88-371-1579-2, pp: 384.

2. Civita, M., G. Sappa and A. Zavatti, 2005. An evaluation practice for hazard sources of groundwater. IGEA, 20: 59-68.

3. Collin, M.L. and A.J. Melloul, 2001. Combined land-use and environmental factors for sustainable groundwater management. Urban Water, 3: 229-237. DOI: 10.1016/S1462-0758(01)00049-8
4. Collin, M.L. and A.J. Melloul, 2003. Assessing groundwater vulnerability to pollution to promote sustainable urban and rural development. J. Cleaner Prod., 11: 727-736. DOI: 10.1016/S09596526(02)00131-2

5. Dal Piaz, G.V., 1992. Cura Di Società Geologica Italiana, Le alpi dal monte bianco al lago maggiore, Alps from monte bianco to lago maggiore. Guide geologiche regionali della società geologica Italiana, 80, Be-Ma Editrice, Milano. ISBN: 887143-123-5 1992, pp: 304.

6. Foster, S.S.D. and R. Hirata, 1988. Groundwater pollution risk assessment. A methodology using available data, WHO/PAHO-CEPIS Technical Manual, Lima, Peru.

http://www.cepis.ops-oms.org/bvsacd/scan/020059.pdf

7. Foster, S.S.D., 2001. The interdependence of groundwater and urbanization in rapidly developing cities. Urban Water, 3: 185-192. DOI: 10.1016/S1462-0758(01)00043-7.

8. Genxu, W., Y. Lingyuan, C. Ling and J. Kubota, 2005. Impacts of land use changes on groundwater resources in the Heihe River Basin. J. Geo. Sci., 15: 405-414. DOI: 10.1007/BF02892147.

9. Haimes, Y.Y., 1984. Risk assessment for the prevention of groundwater contamination. NCR Stud. Geophysics, Groundwater Contamination, ISBN: 0-309-03441-8, pp: 166-169.

10. Holman, D., 1958. Groundwater Potential Pollution Risk Assessment Index. In: Groundwater Protection Principles and Alternatives for Rock County, Wisconsin, Zaporozec, A. (Ed.). pp: 73.

11. Nouri, J. and S. Malmasi, 2005. The role of groundwater vulnerability in urban development planning. Am. J. Environ. Sci., 1: 16-21. http://www.scipub.org/fulltext/ajes/ajes111621.pdf

12. Tacconi E. and A. Zavatti, 1999. Relative pressure weighted indices of anthropogenic activities. (In Italian) 